\title{
Combined detection of mannanaemia and anti- mannan antibodies as a strategy for the diagnosis of systemic infection caused by pathogenic Candida species
}

\author{
BOUALEM SENDID*†, JEAN LOUIS POIROT§, MARC TABOURET†, ALAIN BONNIN\|, \\ DENIS CAILLOT**, DANIEL CAMUS + and DANIEL POULAIN*† \\ * Laboratoire de Mycologie Fondamentale et Appliquée et Equipe Inserm 9915, †Laboratoire de Parasitologie- \\ Mycologie, CHRU, Faculté de Médecine, Pôle Recherche, F-59045 Lille, †Bio-Rad, Route de Cassel, 59114 \\ Steenvoorde, §Laboratoire de Parasitologie-Mycologie, Hôpital Saint Antoine, 75012 Paris, \|Laboratoire de \\ Parasitologie-Mycologie and ** Département d'Hématologie Clinique, Centre Hospitalier Régional Universitaire, \\ Hôpital Le Bocage, Dijon, France
}

\begin{abstract}
A novel strategy for the diagnosis of systemic candidosis was evaluated, based on the combination of two enzyme immunoassays that detect a candida oligomannoside repetitive epitope expressed in large amounts by Candida albicans (Platelia Candida Ag), and antibodies against $C$. albicans mannan, the major cell-wall immunogen in which this epitope is present (Platelia Candida Ab). Sera were selected retrospectively from intensive care and haematology patients with clinically suspected systemic candidosis, and from whom Candida spp. had been isolated from normally sterile sites. Of the 21 patients infected with $C$. albicans, 13 had positive antigenaemia and 14 had a positive antibody response, including eight patients who were antigenaemia negative. The sensitivity of the combined tests was $100 \%$. In patients infected with $C$. glabrata $(n=12)$ or $C$. tropicalis $(\mathrm{n}=10)$, the sensitivity was $83 \%$ and $80 \%$, respectively. For the remaining patients, infected with $C$. parapsilosis $(\mathrm{n}=10)$, C. krusei $(\mathrm{n}=8)$ or $C$. kefyr $(\mathrm{n}=2)$, the sensitivity of the combined tests was $40 \%, 50 \%$ and $50 \%$, respectively. At least one of the serological tests was positive before yeast growth occurred in $60 \%$ of patients for whom a serum sample was available before blood culture sampling. An increase in serological test positivity to $>\mathbf{8 0} \%$ was observed for sera obtained around the date of positive culture, irrespective of the Candida species isolated. These results suggest that regular serological monitoring for both mannanaemia and anti-mannan antibodies in at-risk patients may contribute to the early diagnosis of candidosis.
\end{abstract}

\section{Introduction}

Several Candida species are pervasive pathogens capable of causing systemic infection in critically ill and severely immunocompromised patients [1-4]. In the $1980 \mathrm{~s}$, Candida species were reported to be the seventh most common nosocomial pathogens hospitalwide, ranking fourth in intensive care units (ICUs) where they accounted for $c .10 \%$ of all bloodstream infections [5-7]. This general incidence has continued in the past decade in the USA [8], as well as in Europe

Received 1 June 2001; revised version accepted 17 Nov. 2001.

Corresponding author: Dr D. Poulain (e-mail: dpoulain@ univ-lille2.fr).
[9-12]. Despite the high morbidity and mortality associated with candidosis, no decrease in the incidence of this infection has yet been achieved. Recently, much attention has focused on the increased prevalence of infections caused by non-albicans Candida spp. and the emergence of azole resistance in these yeasts $[13,14]$. The proportion of non-albicans species causing systemic candidosis has been reported to be $46 \%$ overall [15-17]. The greater pathogenicity of C. albicans, C. glabrata and C. tropicalis compared with the other species has been documented, and these species account for $>80 \%$ of all systemic candida infections. In contrast, despite an increase in relative prevalence of $C$. parapsilosis infections, in neonatal patients and patients with intravascular lines, candidosis caused by this species as well as those caused by $C$. 
krusei are less frequent, transient and generally associated with a better prognosis $[18,19]$. Irrespective of the causative species, systemic candidosis is difficult to diagnose clinically and microbiologically. In this respect, continuous efforts are being made to develop methods for the detection of candida DNA [20-23] or metabolites, whose presence in patients' sera could indicate deep tissue invasion [24-26]. Like glucans, mannans are major components of the candida cell wall. However, in contrast to glucans, mannans are bound non-covalently at the cell-wall surface and are highly antigenic [27]. Since the initial description of the presence of mannans in patients' sera by Wiener and Yount [28], concerted efforts have been made to increase the sensitivity of serological tests for mannan detection. Despite progress in this area, mannan detection is still associated with low sensitivity, mainly due to the transient nature of mannanaemia. Despite the lack of sensitivity of these tests, the more recent generation of mannan detection tests is generally considered to be specific [29]. Detection of antimannan antibodies has been recommended as an early diagnostic procedure [30] but is associated with low sensitivity, due to the absence of an antibody response in immunocompromised patients, and low specificity, due to the presence of anti-mannan antibodies in sera from colonised, uninfected patients [30, 31]. In addition to serological procedures, a strategy has recently been proposed to survey at-risk patients to identify those in whom pre-emptive therapy would be justified. This strategy consists of the determination of a colonisation index $(\mathrm{CI})$, defined as the ratio of the number of nonblood distinct body sites colonised by Candida spp. to the total number of distinct body sites tested. A threshold of $\geqslant 0.5$ discriminates between infected and colonised patients $[3,32-36]$. According to some of these studies, the sensitivity and specificity of this procedure were $100 \%$ [35].

In the current study, a strategy for the serological diagnosis of candidosis was developed based on four points: (i) an increase in sensitivity of a previous test (Pastorex Candida) that detects a repetitive oligomannose epitope specific to monoclonal antibody (MAb) EBCA1, expressed on a large number of $C$. albicans molecules; (ii) the detection of antibodies to mannan, the major $C$. albicans immunogen which expresses, among other molecules, the MAb EBCA1 epitope; (iii) the development of standardised immunoassays, with cut-off values determined with appropriate controls, which can be automated and better adapted to the large number of at-risk patients in large university hospitals [37]; and (iv) the monitoring of both antigenaemia and antibody response in individual patients, following the routine diagnostic strategies used for other infectious diseases like hepatitis B and HIV infection [38]. In a preliminary study, the sensitivity and specificity of the combined tests were shown to be $80 \%$ and $93 \%$, respectively, when used to test serum samples collected from 43 patients with systemic candidosis caused by $C$. albicans [37]. These tests are now marketed as Platelia Candida Ag and Platelia Candida Ab, respectively.

MAb EBCA1 recognises sequences of $\alpha$-linked oligomannoses, comprised of more than four residues, present in a large number of mannoproteins extracted from C. glabrata and C. tropicalis, and to a lesser extent $C$. parapsilosis and C. krusei [39]. Thus, it seemed likely that Platelia Candida Ag would also detect antigens of non-albicans Candida spp. The objective of this study was to extend the preliminary results obtained in patients infected with $C$. albicans and explore this possibility by examining a cohort of representative patients infected with different Candida spp. Patients with clinical and mycological evidence of systemic candidosis were selected retrospectively from three French university hospitals. For each patient, the relationship between the time each Platelia test became positive and the time of positive culture from a normally sterile site was investigated.

\section{Materials and methods}

\section{Patients}

A total of 204 sera from 63 patients with proven candidosis was obtained retrospectively between Jan. 1992 and Jan. 2000 from three French university hospitals. Twenty-one patients were infected with $C$. albicans and 42 were infected with non-albicans Candida spp.: C. glabrata (12 patients), C. tropicalis (10), C. parapsilosis (10), C. krusei (8) and C. kefyr (2). The mean number of serum samples per patient was 3.2 (SD 3) (Table 1). The following criteria were applied retrospectively to laboratory and clinical files as selection rules: (i) positive culture for Candida spp. from normally sterile site (blood, bile, pericardial fluid, liver biopsy specimen, drain, wound); (ii) availability of serum samples within a range of 1 week before to 2 weeks after positive culture; (iii) analysis of patients' charts, with special attention to risk factors, i.e., cancer and chemotherapy, malignant haemopathies, abdominal surgery, AIDS, major health problems requiring hospitalisation in ICUs, broad-spectrum antibiotics, indwelling intravascular catheters, hyperalimentation; and (iv) infectious syndrome (fever) not responding to antibacterial therapy but responding to antifungal therapy.

\section{Methods}

A summary of the methods used is shown in Fig. 1.

Detection of anti-mannan antibodies (Platelia ${ }^{\circledR}$ Candida Ab; BioRad Laboratories). Microtitration plates were sensitised with $C$. albicans cell-wall mannan [37]. Mannan is a major, non-covalently bound, cell-wall surface antigen, visualised by electron microscopy with periodic acid-thiocarbohydrazide-silver proteinate staining [40] (Fig. 1a), and is extracted and purified from 
Table 1. Patient information, culture data and results of antibody an antigen testing in the study population

\begin{tabular}{|c|c|c|c|c|c|c|c|c|}
\hline $\begin{array}{l}\text { Patient } \\
\text { no. }\end{array}$ & Sex & $\begin{array}{c}\text { Age } \\
\text { (years) }\end{array}$ & Hospital ward & $\begin{array}{l}\text { Number of } \\
\text { serum } \\
\text { specimens }\end{array}$ & $\begin{array}{l}\text { Candida sp. } \\
\text { isolated }\end{array}$ & Site of isolation & $\begin{array}{c}\text { Peak antigen } \\
\text { concentration } \\
(\mathrm{ng} / \mathrm{ml}) \text { by EIA }\end{array}$ & $\begin{array}{c}\text { Peak antibody } \\
\text { response (AU) } \\
\text { by EIA }\end{array}$ \\
\hline 1 & $\mathrm{~F}$ & 65 & Surgery & 3 & albicans & Blood & 4 & $2.5(2.3)$ \\
\hline 2 & $\mathrm{~F}$ & 58 & Nephrology & 1 & albicans & Blood & 2 & 14 \\
\hline 3 & M & 59 & Oncology & 1 & albicans & Blood & 2 & 17 \\
\hline 4 & $\mathrm{~F}$ & 7 & ICU & 2 & albicans & Blood & 2 & 100 \\
\hline 5 & M & 51 & $\mathrm{ICU}$ & 3 & albicans & Blood & 2 & $0(0)$ \\
\hline 6 & M & 74 & Surgery & 1 & albicans & Blood & 1.75 & 17.5 \\
\hline 7 & M & 53 & Haematology & 5 & albicans & Blood & 1.58 & $2.1(0)$ \\
\hline 8 & M & $10 \mathrm{mths}$ & Surgery & 2 & albicans & Blood & 1.3 & $0(0)$ \\
\hline 9 & M & 29 & ICU & 2 & albicans & Blood & 1.2 & $2(0)$ \\
\hline 10 & M & 75 & Surgery & 2 & albicans & Blood & 1.1 & $42(37.5)$ \\
\hline 11 & $\mathrm{~F}$ & 24 & Surgery & 1 & albicans & Blood & 0.8 & 13 \\
\hline 12 & $\mathrm{~F}$ & 73 & $\mathrm{ICU}$ & 3 & albicans & Blood & 0.67 & $2(2)$ \\
\hline 13 & M & 51 & Surgery & 1 & albicans & Blood & 0.61 & 9 \\
\hline 14 & M & 49 & Surgery & 3 & albicans & Blood & 0.4 & 11 \\
\hline 15 & $\mathrm{~F}$ & 76 & Surgery & 4 & albicans & Blood & 0.34 & 11 \\
\hline 16 & $\mathrm{M}$ & 64 & Surgery & 3 & albicans & Blood & 0.23 & 40 \\
\hline 17 & $\mathrm{~F}$ & 50 & Surgery & 1 & albicans & Blood & 0.18 & 19 \\
\hline 18 & $\mathrm{~F}$ & 73 & $\mathrm{ICU}$ & 1 & albicans & Blood & 0 & 40 \\
\hline 19 & M & 68 & Gastroenterology & 4 & albicans & Blood & 0 & 15.2 \\
\hline 20 & M & 74 & Surgery & 2 & albicans & Blood & 0 & 43 \\
\hline 21 & $\mathrm{~F}$ & 47 & Surgery & 1 & albicans & Blood & 0 & 19.2 \\
\hline 22 & $\mathrm{~F}$ & 66 & Surgery & 1 & glabrata & Blood & 4.73 & 0 \\
\hline 23 & $\mathrm{~F}$ & 76 & Surgery & 2 & glabrata & Blood & 2.8 & 4 \\
\hline 24 & M & 50 & ICU & 1 & glabrata & Blood & 2 & 7 \\
\hline 25 & $\mathrm{~F}$ & 48 & Haematology & 5 & glabrata & Blood & 1.05 & 1 \\
\hline 26 & $\mathrm{~F}$ & 18 & Haematology & 6 & glabrata & Blood & 1.04 & 0 \\
\hline 27 & M & 67 & Surgery & 1 & glabrata & Blood & 0.81 & 2 \\
\hline 28 & $\mathrm{~F}$ & 69 & Haematology & 3 & glabrata & Blood & 0.71 & 5 \\
\hline 29 & $\mathrm{~F}$ & 70 & Cardiology & 1 & glabrata & Blood & 0.02 & 18 \\
\hline 30 & $\mathrm{~F}$ & 74 & Endocrinology & 1 & glabrata & Blood & 0 & 34.4 \\
\hline 31 & $\mathrm{~F}$ & 71 & ICU & 1 & glabrata & Blood & 0 & 22 \\
\hline 32 & $\mathrm{~F}$ & 58 & ICU & 7 & glabrata & Blood & 0 & 3 \\
\hline 33 & $\mathrm{~F}$ & 72 & Surgery & 2 & glabrata & Blood & 0 & 0 \\
\hline 34 & M & 63 & Gastroenterology & 1 & tropicalis & Blood & 10 & 8 \\
\hline 35 & $\mathrm{~F}$ & 55 & Haematology & 9 & tropicalis & Blood, CSF & 5.6 & $18.4(0)$ \\
\hline 36 & M & 31 & Haematology & 8 & tropicalis & Blood & 2.9 & $13.4(5.4)$ \\
\hline 37 & $\mathrm{~F}$ & 40 & Haematology & 26 & tropicalis & BUC & 2.8 & $12.3(0)$ \\
\hline 38 & $\mathrm{M}$ & 60 & Haematology & 15 & tropicalis & Blood & 2.5 & $55(5)$ \\
\hline 39 & $\mathrm{~F}$ & 70 & Haematology & 6 & tropicalis & Blood, bone biopsy & 1.08 & 0.74 \\
\hline 40 & M & $\mathrm{P}$ & Surgery & 4 & tropicalis & Blood & 0.92 & $41.2(29)$ \\
\hline 41 & $\mathrm{~F}$ & 36 & Surgery & 1 & tropicalis & Blood & 0 & 58 \\
\hline 42 & M & 45 & Burns & 1 & tropicalis & Blood & 0 & 0 \\
\hline 43 & M & 52 & $\mathrm{ICU}$ & 1 & tropicalis & Blood & 0 & 0 \\
\hline 44 & $\mathrm{~F}$ & 50 & Surgery & 5 & parapsilosis & Blood & 3.02 & 1.3 \\
\hline 45 & $\mathrm{M}$ & 48 & Surgery & 1 & parapsilosis & Blood & 1.6 & 12 \\
\hline 46 & $\mathrm{~F}$ & 54 & Surgery & 2 & parapsilosis & Blood & 1.18 & $1.7(1.5)$ \\
\hline 47 & M & 64 & Surgery & 1 & parapsilosis & Blood & 0.12 & 20 \\
\hline 48 & $\mathrm{~F}$ & 75 & Surgery & 2 & parapsilosis & Blood & 0.42 & 2 \\
\hline 49 & M & 57 & Surgery & 4 & parapsilosis & Blood & 0.33 & 7 \\
\hline 50 & $\mathrm{~F}$ & 74 & ICU & 3 & parapsilosis & Peritoneum & 0.11 & 0 \\
\hline 51 & M & 34 & Burns & 2 & parapsilosis & Blood & 0 & 9 \\
\hline 52 & $\mathrm{~F}$ & 55 & Surgery & 5 & parapsilosis & Blood & 0 & 4 \\
\hline 53 & $\mathrm{H}$ & 44 & Oncology & 4 & parapsilosis & Blood & 0 & 0 \\
\hline 54 & $\mathrm{~F}$ & 30 & Infectious Dis. & 2 & krusei & Blood & 0.61 & $52(0)$ \\
\hline 55 & M & 56 & ICU & 3 & krusei & Blood & 0.5 & 0 \\
\hline 56 & $\mathrm{~F}$ & 58 & Haematology & 2 & krusei & Blood & 0 & 34 \\
\hline 57 & $\mathrm{~F}$ & 55 & Surgery & 2 & krusei & Blood & 0.23 & 6.6 \\
\hline 58 & $\mathrm{M}$ & 64 & ICU & 4 & krusei & Peritoneum & 0.21 & 0 \\
\hline 59 & $\mathrm{~F}$ & 48 & Infectious Dis. & 5 & krusei & KT & 0.11 & 4 \\
\hline 60 & M & 31 & Infectious Dis. & 2 & krusei & Blood & 0 & 27 \\
\hline 61 & M & 76 & Surgery & 1 & krusei & Spleen & 0 & 3 \\
\hline 62 & $\mathrm{~F}$ & 75 & Surgery & 3 & kefyr & Spleen & 5 & 80 \\
\hline 63 & M & 56 & Surgery & 2 & kefyr & Abscess & 0 & 4.8 \\
\hline
\end{tabular}

M, male; F, female; CSF, cerebrospinal fluid; BUC, blood, urine and cutaneous samples. Bold type indicates positive results. Values in parentheses are antimannan antibody titre detection in the same sample which presented a peak of antigenaemia. 
a
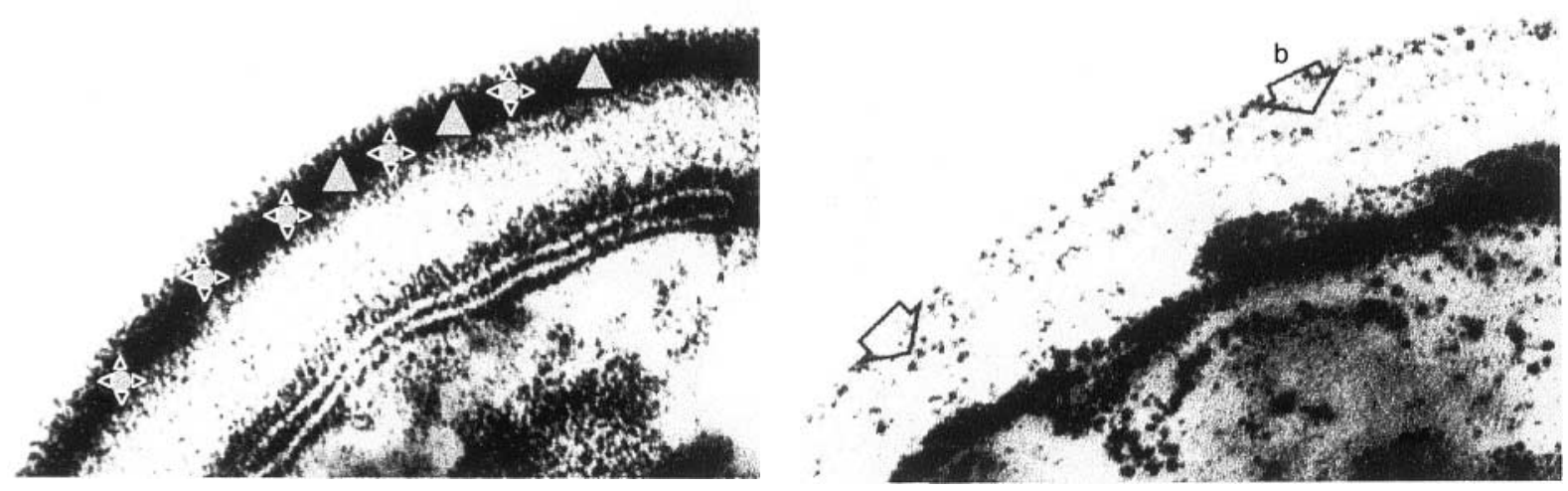

d
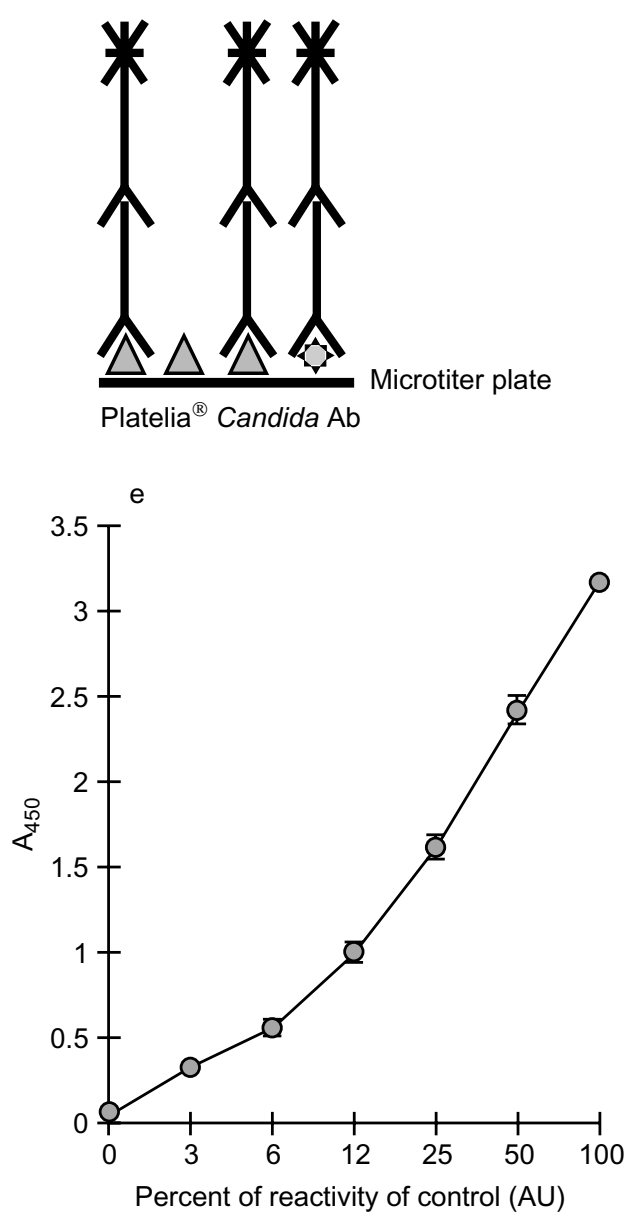

c

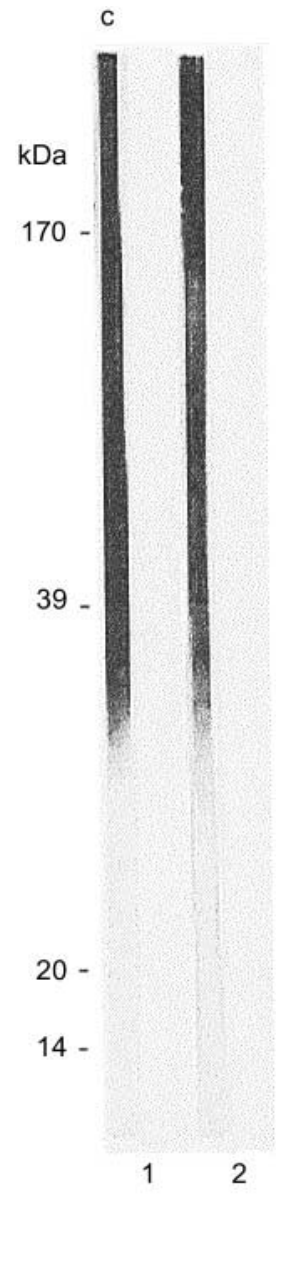

f

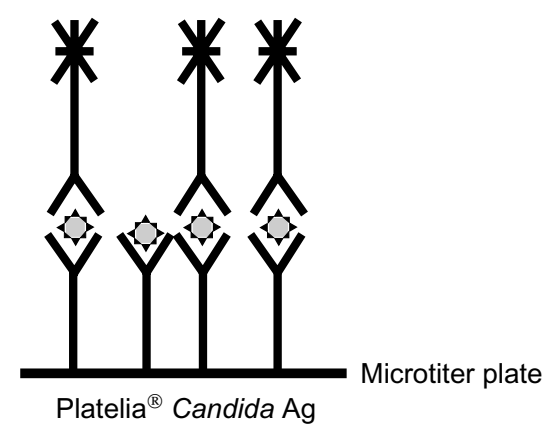

Platelia ${ }^{\circledR}$ Candida Ag

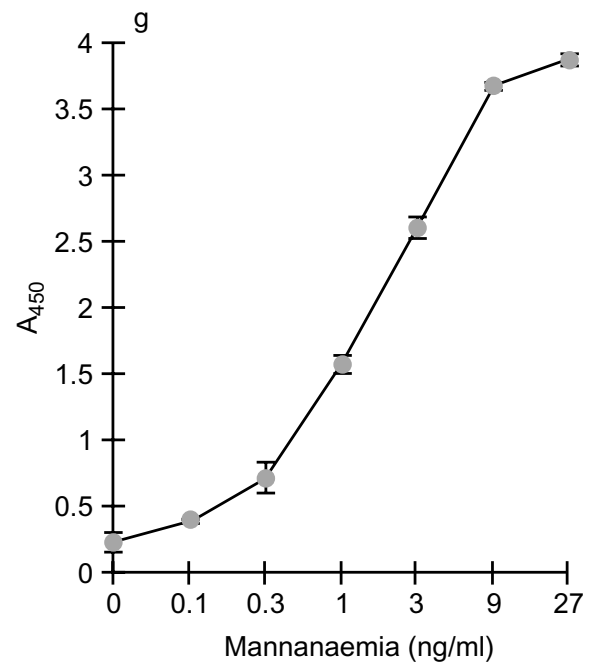

Fig. 1. Schematic representation of the steps involved in the diagnostic tests for the detection of anti-mannan antibodies (Platelia ${ }^{\circledR}$ Candida $\mathrm{Ab}$ ) and mannanaemia (Platelia ${ }^{\circledR}$ Candida Ag) in sera from patients with systemic candidosis. a, b, C. albicans cell-wall mannan revealed by electron microscopy with periodic acid-thiocarbohydrazide staining, before and after autoclaving; c, PAGE of mannan stained with concanavalin A (lane 1) or MAb EBCA1 (2) after electrotransfer on to nitrocellulose; d, detection of antimannan antibodies including those specific for MAb EBCA1 epitopes, the reaction is revealed with horseradish peroxidaseconjugated anti-human immunoglobulins; e, individual titres are reported in arbitrary units in relation to the standard curve; f, detection of circulating EBCA1 repetitive epitopes, MAb EBCA1 is used as captor and detector; g, calibration curve obtained with a pool of normal human sera supplemented with different concentrations of mannan.

candida cells by autoclaving [41] (Fig. 1b). The mannan involved in the test was prepared from $C$. albicans strain VW32 grown in bioreactors [42]. As revealed by polyacrylamide gel electrophoresis (PAGE) and electrotransfer, this mannan appeared as a highly polydispersed molecule when stained with concanavalin
A, a lectin which reacts with $\alpha$-mannosyl residues [43] (Fig. 1c, lane 1). The primary and secondary antibody binding steps, as shown in Fig. 1d, have been described previously [37]. The reactions were performed with the BEP III Automate (Dade-Behring Laboratories, France). Each set of tests included a standard curve 
which consisted of serial two-fold dilutions of a pool of sera strongly reacting with yeast mannan (Fig. 1e). The absorbance was measured at $\lambda=450 / 620 \mathrm{~nm}$. Results were reported in arbitrary units (AU) determined in relation to the standard curve; $10 \mathrm{AU}$ were considered to indicate candidosis [37].

Detection of mannanemia (Platelia ${ }^{\circledR}$ Candida Ag; BioRad Laboratories). This test involves MAb EBCA1, used previously in a latex agglutination test (Pastorex Candida; BioRad Laboratories, Marnes-LaCoquette, France). MAb EBCA1 recognises an epitope present in mannan (Fig. 1), and binding of the antibody almost superimposes concanavalin A staining (Fig. 1c, lane 2). Because of the repetitive nature of the epitope on C. albicans molecules [43], the assay involves MAb EBCA1 as both a captor and detector antibody (Fig. 1f) [37].

Serum samples $(300 \mu \mathrm{l})$ from patients were denatured with $100 \mu \mathrm{l}$ of EDTA treatment solution, boiled for $3 \mathrm{~min}$ and centrifuged for $10 \mathrm{~min}$ at $10000 \mathrm{~g}$. Then $50 \mu 1$ of supernate were mixed in EBCA1-coated wells with $50 \mu \mathrm{l}$ of horseradish peroxidase-conjugated EBCA1. After incubation for $90 \mathrm{~min}$ at $37^{\circ} \mathrm{C}$, the plates were washed thoroughly and the reaction was revealed after incubation for $30 \mathrm{~min}$ in the dark with tetramethylbenzidine solution $200 \mu \mathrm{l}$. The optical density was read at $\lambda=450 / 620 \mathrm{~nm}$ on a PR2100 reader (BioRad Laboratories). All reactions were performed in duplicate. Each experiment included a calibration curve, which involved a pool of normal human sera supplemented with known concentrations of mannan $(0.1-27 \mathrm{ng} / \mathrm{ml}$; Fig. 1g).

\section{Results}

The results obtained for the 63 patients are summarised in Table 1. Patients were divided into six groups, depending on the Candida sp. involved. The maximum mannanaemia or anti-mannan antibody response, or both, observed in at least one of the serum samples from each patient is shown.

\section{Results for each serum sample}

Fig. 2 shows the individual values for the 408 tests performed on the 204 serum specimens obtained from the 63 patients with candidosis. Each antigenaemia value, expressed in $\mathrm{ng} / \mathrm{ml}$, is represented either by a closed or open circle for positive or negative antibody responses, respectively. Antigenaemia values were plotted as a function of the date of serum sampling. This method of expressing the results shows the nature of the serum samples in relation to the date of positive mycological examination (PME) corresponding to day 0 , but does not take into account the Candida sp. isolated. This information is given in Table 2, in relation to the date of PME. Fig. 3 shows the cumulative sensitivity of each test and of the combination of tests, for each serum sample and for each species, as a function of the time of serum sampling. The graph has been split in two parts

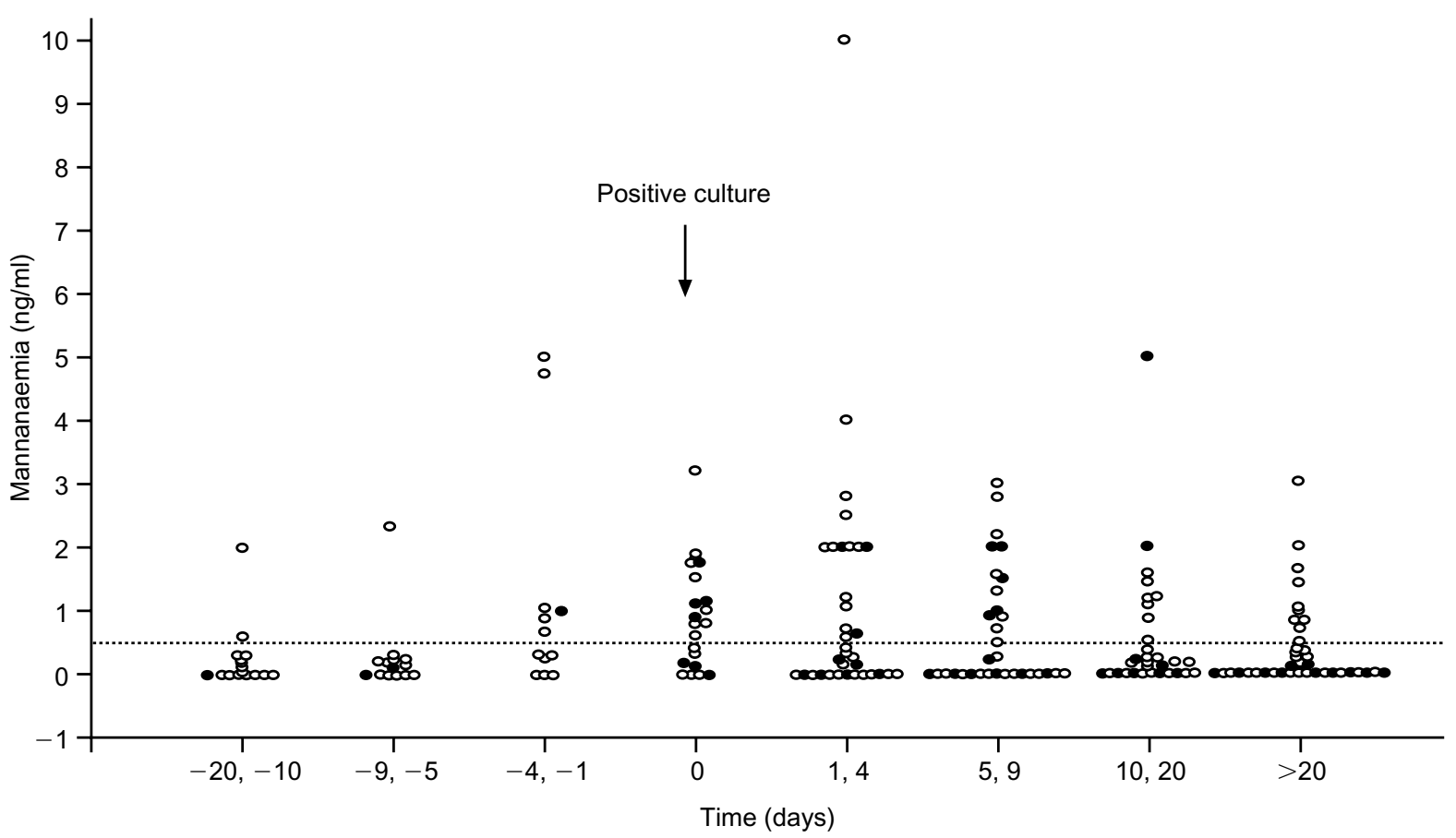

Fig. 2. Individual mannanaemia values for the 204 sera tested plotted as a function of the date of serum sampling. Arrow indicates the date of isolation of Candida sp. from sterile sites. Depending on the antibody response associated with the serum sample, $\bigcirc$ represent non-significant titres $(<10 \mathrm{AU})$ and - represent a positive antibody response. The horizontal dotted line represents $0.5 \mathrm{ng} / \mathrm{ml}$, which is the cut-off value of the mannanaemia test. 

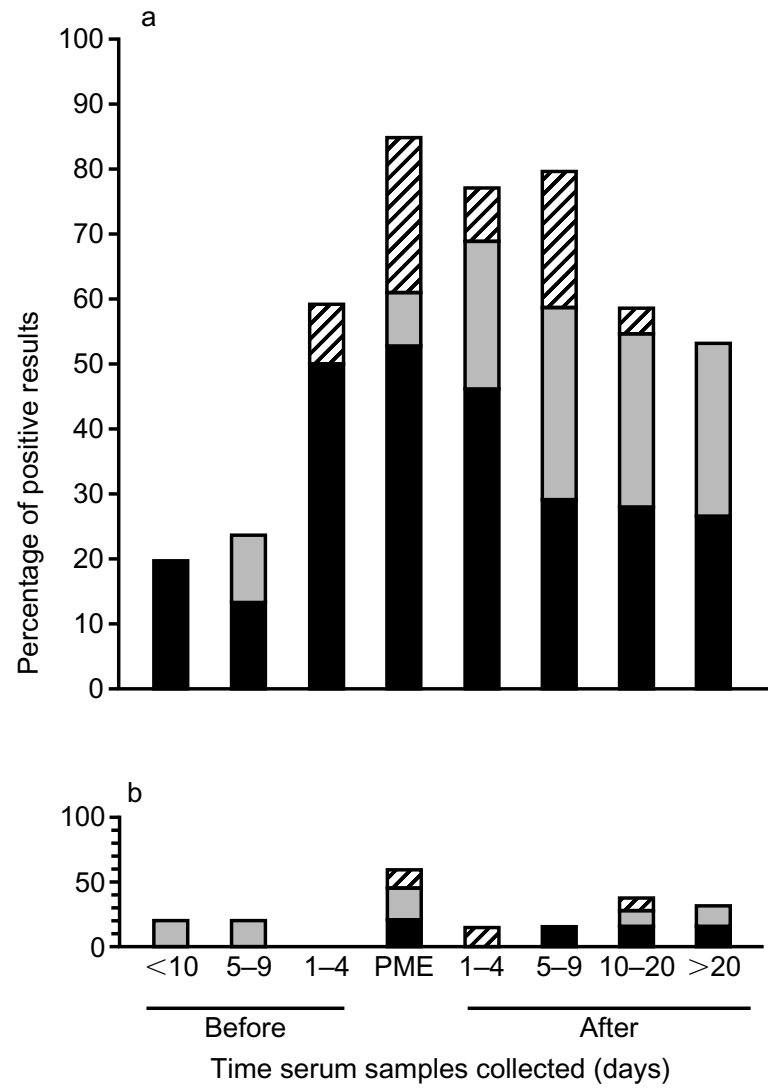

Fig. 3. Sensitivity (per serum sample) of antigen ( $\square$ ) and antibody $(\square)$ detection tests, and the combination $(\square)$ as a function of time of serum sampling. (a) Results of sera from patients infected with the main pathogenic Candida spp. (C. albicans, C. glabrata, C. tropicalis; c. $80 \%$ of all clinical isolates). (b) Results of sera obtained from patients infected with other yeasts. PME (day 0) indicates the date of isolation of a Candida sp. from normally sterile sites.

according to the relative prevalence of nosocomial infection caused by Candida spp. i.e., Fig. 3a shows the results for patients infected by the predominant pathogenic Candida spp. (C. albicans, C. glabrata, C. tropicalis). Positive mannanaemia was observed 2 weeks before mycological detection. The percentage of antigen-positive sera increased with time to reach a maximum of $67 \%$ around the days of positive mycological isolation, thereafter decreasing slowly. The onset of an antibody response was delayed slightly when compared with antigenaemia and reached a maximum 1 week after mycological detection. On the day of mycological detection, the cumulative sensitivity of both tests was maximum and reached $85 \%$. Fig. $3 \mathrm{~b}$ represents the results obtained with sera from patients infected with C. parapsilosis, C. krusei or C. kefyr. The performance of the tests in detecting these latter species was not as powerful as for the earlier species. Nevertheless it was possible to see a similar trend of increased sensitivity of both tests around the date of positive mycological investigations.

\section{Results for each patient}

A previous study with a large number of control sera showed that the specificity of combined mannan and anti-mannan antibody detection by EIA was 93\% [37]. Of the 21 patients infected with C. albicans in the current study, 13 had positive tests for antigenaemia and 14 had a positive antibody response, including eight patients who were negative for antigenaemia. The sensitivity of the combined tests was $100 \%$. Of the 12 patients infected with C. glabrata, seven had positive antigenaemia, but in three the lack of detectable antigen was associated with the presence of a significant titre of antibodies ( $>18 \mathrm{AU})$. Both tests remained constantly negative for two patients. Therefore, in this series the combined sensitivity of both tests was $83 \%$. Of the 10 patients infected with $C$. tropicalis, seven had positive antigenaemia and six had positive antibody tests. Both tests were negative in two patients for whom only one serum sample was available. Thus, the sensitivity of the combined tests in this series of $C$. tropicalis infection was $80 \%$. Twenty patients were infected with C. parapsilosis, C. krusei and C. kefyr, and the combined sensitivities of the tests were $40 \%$, $50 \%$ and $50 \%$, respectively.

Although the numbers of serum samples per patient vary from one to 26 , some information can be derived from this study about the kinetics of antigenaemia. Persistence, or at least constantly positive antigen tests,

Table 2. Results obtained on serum samples available in relation to positive mycological examination (PME) and Candida species

\begin{tabular}{|c|c|c|c|c|c|c|c|c|c|c|c|c|c|}
\hline \multirow{2}{*}{ Species } & \multirow{2}{*}{$\mathrm{n}$} & \multicolumn{12}{|c|}{ Number of samples examined } \\
\hline & & \multicolumn{4}{|c|}{ Before PME } & \multicolumn{4}{|c|}{ Day of PME } & \multicolumn{4}{|c|}{ After PME } \\
\hline C. albicans & 46 & 4 & 0 & 0 & 6 & 2 & 1 & 3 & 1 & 7 & 13 & 4 & 5 \\
\hline C. glabrata & 31 & 2 & 0 & 0 & 2 & 1 & 0 & 0 & 0 & 6 & 3 & 0 & 17 \\
\hline C. tropicalis & 72 & 2 & 2 & 1 & 9 & 4 & 0 & 0 & 1 & 25 & 16 & 4 & 8 \\
\hline C. parapsilosis & 29 & 0 & 0 & 0 & 6 & 1 & 1 & 1 & 1 & 2 & 0 & 0 & 17 \\
\hline C. krusei & 21 & 0 & 2 & 0 & 7 & 0 & 1 & 0 & 2 & 1 & 1 & 0 & 7 \\
\hline C. kefyr & 5 & 0 & 0 & 0 & 0 & 0 & 0 & 0 & 0 & 0 & 1 & 2 & 2 \\
\hline
\end{tabular}

For each species, at a given time: $\mathrm{Ag}+, \mathrm{Ab}+, \mathrm{Ag}+\mathrm{Ab}+$ and $\mathrm{Ag}-\mathrm{Ab}-$ represent the number of sera exhibiting positive antigenaemia (without antibody); positive antibody response (without antigenaemia); positive antigen and antibody response; and negative results with both tests, respectively. 
was observed (patient 37) for a maximal period of 50 days during which 15 samples were drawn. This patient (hospitalised in a haematology ward) never developed an antibody response during this period. For some patients, disappearance or appearance of antigenaemia was observed within 3-day intervals. In general, the more samples that were available the more chance there was of observing positive antigenaemia. For $C$. albicans, C. tropicalis and C. glabrata infections, the mean number of serum samples for patients who displayed at least one antigen-positive test was 4.2 (SD 5.4) versus 2.7 (SD 1.9) for patients for whom no positive test was observed. For infections caused by $C$. albicans, C. tropicalis or C. glabrata, comparison of the results for each patient according to the ward where they were being treated (ICU or haematology) gave the following results: sensitivity of Platelia Candida $\mathrm{Ag}$ was $55 \%$ and $90 \%$, respectively, and sensitivity of Platelia $\mathrm{Ab}$ was $30 \%$ and $44 \%$, respectively.

\section{Discussion}

Because of the absence of specific clinical signs and symptoms, systemic candidosis remains a diagnostic and therapeutic challenge [29,44,45]. Diagnosis is generally supported by a compendium of clinical [46], radiological [47-49] and mycological evidence [50]. Efforts made to include the results of serological tests in this compendium have generally failed, despite consistent improvements in the sensitivity and specificity of these tests, particularly those detecting candidaderived molecules such as D-arabinitol [26], glucans [25] and mannan [24, 51]. By changing the format of the test for the detection of mannan from a latex agglutination test (Pastorex) to an EIA (Platelia Ag), the sensitivity of mannan detection has been increased 10 -fold. This has lead to an increase in sensitivity per patient from $28 \%$ to $40 \%$ with no loss of specificity, as evaluated with a large number of control sera including 93 sera from ICU patients [37]. The specificity of Platelia $\mathrm{Ab}$, evaluated under the same conditions, was $94 \%$ when a cut-off value of $10 \mathrm{AU}$ was used, as described previously [37]. This specificity is acceptable and contrasts with the general current negative opinion about antibody detection tests [29]. We believe that this opinion is based on a misunderstanding of the usage and limits of these tests, and this point needs further discussion. In a pioneering study in 1971 on systemic candidosis in patients with acute leukaemia, the authors came to the following conclusion 'We recommend serial determination of anti-Candida agglutinating antibody titres in groups of patients known to have increased susceptibility to fungal infections as this is the most reliable means for diagnosing visceral candidiasis' [30]. Following the observation that an antibody response developed as candida colonisation in hospitalised patients increased [31,52], confidence in the specificity of these tests decreased. Despite several studies demonstrating the usefulness of anti-Candida antibody detection tests for diagnosis [53, 54], these tests are seldom requested by physicians in clinical practice. The reason given is the absence of clear-cut discrimination between infected and colonised patients. However, studies conducted either in ICUs $[36,55]$ or clinical haematology wards $[33,56]$ have firmly established colonisation as an independent risk factor for systemic candidosis. This makes sense in relation to the natural pathophysiology of systemic candidosis, which is a dynamic process. Most cases of systemic candidosis are endogenous in origin with a continuum from colonisation to infection $[34,45]$. When defining patient categories to determine the cut-off values for antibody detection tests, the question is at which stage should patients be considered? Depending on whether the aim is to provide an early diagnosis or a firm diagnosis, the cut-off value will be a compromise between sensitivity and specificity. Similarly, considering that colonisation is a risk factor and that the development of antibody response parallels colonisation, why should an antibody response not be taken into consideration in clinical surveys? Prospective studies are now underway to assess the possible link between a candida antibody response and CI predictive values.

Together with the antibody detection test, a test for the detection of antigenaemia was also evaluated, which detected the epitope expressed on the antigen used for antibody detection accounting, at least in part, for the complementary nature of both tests. On the one hand, a strong antibody response should result in immune complexes leading to a more rapid clearance of antigen, whereas, on the other hand, high circulating antigen levels, which complex antibodies in vivo, may prevent the detection of antibodies.

In the present study, the clinical usefulness of mannanrelated antigen and anti-mannan antibody detection tests was confirmed in 21 new episodes of $C$. albicans infection. The performance of these tests was preserved when infections caused by C. glabrata and C. tropicalis were also considered. When the 43 infectious episodes caused by C. albicans, C. glabrata and C. tropicalis were combined, the overall sensitivity for the simultaneous detection of circulating mannan and antimannan antibodies was $91 \%$. However, in the case of infections caused by C. parapsilosis, C. kefyr and C. krusei (c. $20 \%$ of all infections) the contribution of both tests to the diagnosis was poor. Despite the availability of serum samples from the majority of patients, the sensitivity of the Platelia Candida Ag test was only $30 \%$ for infections caused by these latter species. Differences in sensitivity of antigen detection depending on the Candida species is consistent with the nature of the candida mannose epitope recognised by MAb EBCA1 used in the test. This MAb recognises an epitope present in large amounts on numerous mannoproteins of $C$. albicans (most of those stained by concanavalin A, a lectin specific for terminal $\alpha$-D- 
mannopyranosyl residues) [43]. This property is important when considering the sensitivity of the test (i.e., the more epitope that is present, the more chance it has of being detected) and also for development of a two-site immunoenzymetric assay (previously sandwich ELISA) which requires the repetitive expression of epitopes on molecules. The MAb EBCA1 epitope was also found in large amounts on mannoproteins of $C$. glabrata, C. tropicalis and C. guilliermondii, but was present to a lesser extent on mannoproteins of $C$. krusei, C. kefyr and C. parapsilosis [39, 57].

Non-significant or low antibody titres were detected in sera from patients infected with $C$. parapsilosis, $C$. kefyr and C. krusei. The sensitivity of the Platelia Candida $\mathrm{Ab}$ test was only $20 \%$ in patients infected with these species. This can be explained by the low level of cross-reactivity between $C$. albicans serotype A mannan used as the antigen and the natural immunogen. The structure and antigenicity of candida mannans have been elucidated through a series of excellent studies conducted in Japan. It has been demonstrated that Candida strains exhibit different antigenic factors in their mannan depending on the species. Each of these factors correspond to sequences of mannose residues recognised by rabbit polyclonal IgG and listed as $1,4,5,6,8,9,11,13,13 \mathrm{~b}, 34$ IgGs. Combination of these IgGs is species-specific [58]. Based on this serological classification, the mannan used as the antigen in the Platelia Candida $\mathrm{Ab}$ test displays serum factors $1,4,5$ and 6 [27]. At least three of these major antigenic factors are shared by $C$. tropicalis and $C$. glabrata, and this may explain the high level of crossreactivity with sera obtained from patients infected with these Candida spp. Only factor 1 is shared between $C$. albicans, C. parapsilosis, $C$. kefyr and $C$. krusei, and this could explain the poor performance of Platelia Candida $\mathrm{Ab}$ in detection of infection with these species. However, the reason for the disparities in antibody and antigen detection in patients infected by the latter species is unknown, although the possibility of mixed candida infection, which occurs in clinical practice, cannot be excluded $[59,60]$.

As far as the ability of the two tests to diagnose candida infection early is concerned, conclusions can only be drawn from the sera available because of the retrospective nature of this study. For 25 of the 63 patients included in this study, at least one serum sample was available before mycological evidence of infection was obtained. Eight of these patients had detectable mannanaemia (in the absence of significant anti-mannan antibodies), three had significant antimannan antibody levels (in the absence of mannanaemia), and one had both antigen and antibodies. The sera from the 13 remaining patients were negative in both tests. Evidence for antigenaemia and an antibody response was obtained on average 1 week (8.12 SD 3.8 days) before isolation of Candida spp. Thus, the use of both tests allowed an early diagnosis in c. 50\% of patients for whom at least one serum sample was available before mycological isolation. Considering the high mortality rate (40-60\%) associated with candida infection [45], the prognosis could have been improved for 16 patients by early diagnosis and rapid institution of antifungal therapy. As shown by the increased sensitivity of the tests observed around the day of mycological detection, and the relationship evidenced between the number of available sera per patient and positivity of tests, it is anticipated that this number could be increased by regular serological sampling [51]. Complementation of the tests was observed in whatever clinical service at-risk patients were hospitalised. Haematology patients are known to be unable to develop an antibody response during periods of cytopenia, when candida infection may only be demonstrated by antigen detection and most of the sera available from these patients were drawn during the cytopenia period, which explains the higher proportion of positive antigen tests. However, before and after this period, antibodies are produced during infection and antigen detection tests become negative. This phenomenon is particularly evident in the follow-up of patients who have developed candida infection during a prolonged hospital stay [61]. In ICUs, many factors such as poor nutrition, trauma, hypotension, therapy with steroids or cyclosporine, ischaemia and reperfusion have been related to transitory immunosuppression or damage to the integrity of the gastrointestinal mucosa [10]. This could also explain the complementation of antigen and antibody detection tests observed consistently in these patients during candida infection.

Therefore, in both haematology and ICUs, the combined use of Platelia $\mathrm{Ag}$ and $\mathrm{Ab}$ tests led to a relatively good sensitivity. To date, all negative controls including sera from hospitalised, colonised, uninfected patients and patients with non-candida infections, such as aspergillosis or cryptococcosis - have shown that these tests have good specificity.

Diagnosis of systemic candidosis is difficult $[62,63]$. Development of infection is based on a complex and poorly understood pathophysiology which depends on both pathogenicity determinants of Candida spp. or strains, the primary illness of the patient and medicosurgical practices designed to control it. Modern trends to manage this problem clinically consist of assessing risk factors prospectively $[45,64]$. Blood cultures and mycological surveillance of colonisation have been proposed as microbiological contributions to diagnosis [10]. The present study suggests that inclusion of serological tests in the clinico-biological survey of atrisk patients may be a useful contribution to the diagnosis.

We are grateful to Dr Mahmoud Ghannoum for helpful comments and help in manuscript editing. This work is dedicated to the memory of Dr Jeanine Fruit, who contributed so much to medical mycology in northern France. We thank Laurence Richard and Nadine François for their valuable technical assistance. This work was supported by a 
grant from the 'Centre Hospitalier Régional et Universitaire de Lille, Programme Hospitalier de Recherche Clinique', 1997, no. 1918.

\section{References}

1. Pfaller MA. Epidemiology and control of fungal infections. Clin Infect Dis 1994; 19 Suppl 1: S8-S13.

2. Pfaller MA. Epidemiology of candidiasis. J Hosp Infect 1995; 30 Suppl: $329-338$

3. Wey SB, Mori M, Pfaller MA, Woolson RF, Wenzel RP. Risk factors for hospital-acquired candidemia. A matched casecontrol study. Arch Intern Med 1989; 149: 2349-2353.

4. Wiley JM, Smith N, Leventhal BG et al. Invasive fungal disease in pediatric acute leukemia patients with fever and neutropenia during induction chemotherapy: a multivariate analysis of risk factors. J Clin Oncol 1990; 8: 280-286.

5. Beck-Sagué CM, Jarvis WR and the National Nosocomial Infections Surveillance System. Secular trends in the epidemiology of nosocomial fungal infections in the United States, 1980-1990. J Infect Dis 1993; 167: 1247-1251.

6. Jarvis WR, Edwards JR, Culver DH et al. Nosocomial infection rates in adult and pediatric intensive care units in the United States. National Nosocomial Infections Surveillance System. Am J Med 1991; 91: 185S-191S.

7. Jarvis WR, Martone WJ. Predominant pathogens in hospital infections. J Antimicrob Chemother 1992; 29 Suppl A: 19-24.

8. Edmond MB, Wallace SE, McClish DK, Pfaller MA, Jones RN, Wenzel RP. Nosocomial bloodstream infections in United States hospitals: a three-year analysis. Clin Infect Dis 1999; 29: 239-244.

9. Pfaller MA, Jones $\mathrm{RN}$, Doern $\mathrm{GV}$ et al. International surveillance of blood stream infections due to Candida species in the European SENTRY Program: species distribution and antifungal susceptibility including the investigational triazole and echinocandin agents. SENTRY Participant Group (Europe). Diagn Microbiol Infect Dis 1999; 35: 19-25.

10. Vincent JL, Anaissie E, Bruining H et al. Epidemiology, diagnosis and treatment of systemic Candida infection in surgical patients under intensive care. Intensive Care Med 1998; 24: 206-216.

11. Vincent J-L, Bihari DJ, Suter PM et al. The prevalence of nosocomial infection in intensive care units in Europe. Results of the European Prevalence of Infection in Intensive Care (EPIC) Study. JAMA 1995; 274: 639-644.

12. Voss A, Kluytmans JA, Koeleman JG et al. Occurrence of yeast bloodstream infections between 1987 and 1995 in five Dutch university hospitals. Eur J Clin Microbiol Infect Dis 1996; 15: 909-912.

13. Klepser ME, Ernst EJ, Pfaller MA. Update on antifungal resistance. Trends Microbiol 1997; 5: 372-375.

14. Nguyen MH, Peacock JE, Morris AJ et al. The changing face of candidemia: emergence of non-Candida albicans species and antifungal resistance. Am J Med 1996; 100: 617-623.

15. Pfaller MA. Nosocomial candidiasis: emerging species, reservoirs, and modes of transmission. Clin Infect Dis 1996; 22 Suppl 2: S89-S94

16. Rex JH, Pfaller MA, Barry AL, Nelson PW, Webb CD. Antifungal susceptibility testing of isolates from a randomized, multicenter trial of fluconazole versus amphotericin $\mathrm{B}$ as treatment of nonneutropenic patients with candidemia. NIAID Mycoses Study Group and the Candidemia Study Group. Antimicrob Agents Chemother 1995; 39: 40-44.

17. Wingard JR. Importance of Candida species other than $C$. albicans as pathogens in oncology patients. Clin Infect Dis 1995; 20: $115-125$.

18. Inoue $\mathrm{Y}$, Kohno $\mathrm{S}$, Fujii $\mathrm{T}$ et al. Clinical evaluation of catheter-related fungemia and bacteremia. Intern Med 1995; 34: 485-490.

19. McQuillen DP, Zingman BS, Meunier F, Levitz SM. Invasive infections due to Candida krusei: report of ten cases of fungemia that include three cases of endophthalmitis. Clin Infect Dis 1992; 14: 472-478.

20. Bougnoux M-E, Dupont C, Mateo J et al. Serum is more suitable than whole blood for diagnosis of systemic candidiasis by nested PCR. J Clin Microbiol 1999; 37: 925-930.

21. Chryssanthou E, Klingspor L, Tollemar J et al. PCR and other non-culture methods for diagnosis of invasive Candida infections in allogeneic bone marrow and solid organ transplant recipients. Mycoses 1999; 42: 239-247.

22. Morace G, Pagano L, Sanguinetti M et al. PCR-restriction enzyme analysis for detection of Candida DNA in blood from febrile patients with hematological malignancies. $J$ Clin Microbiol 1999; 37: 1871-1875.

23. Reiss E, Tanaka K, Bruker G et al. Molecular diagnosis and epidemiology of fungal infections. Med Mycol 1998; 36 Suppl 1: $249-257$.

24. Mitsutake K, Miyazaki T, Tashiro T et al. Enolase antigen, mannan antigen, Cand-Tec antigen, and beta-glucan in patients with candidemia. J Clin Microbiol 1996; 34: 1918-1921.

25. Obayashi T, Yoshida M, Mori T et al. Plasma $(1 \rightarrow 3)$-beta-Dglucan measurement in diagnosis of invasive deep mycosis and fungal febrile episodes. Lancet $1995 ; \mathbf{3 4 5}$ : 17-20.

26. Switchenko AC, Miyada CG, Goodman TC et al. An automated enzymatic method for measurement of D-arabinitol, a metabolite of pathogenic Candida species. J Clin Microbiol 1994; 32: 92-97.

27. Suzuki S. Immunochemical study on mannans of genus Candida. I. Structural investigation of antigenic factors 1,4 5, 6, 8, 9, 11, 13, 13b and 34. Curr Top Med Mycol 1997; 8: $57-70$.

28. Wiener MH, Yount WJ. Mannan antigenemia in the diagnosis of invasive Candida infection. J Clin Invest 1976; 58: $1045-1054$.

29. Reiss E, Morrison CJ. Nonculture methods for diagnosis of disseminated candidiasis. Clin Microbiol Rev 1993; 6: 311-323.

30. Preisler HD, Hasenclever HF, Henderson ES. Anti-Candida antibodies in patients with acute leukemia. A prospective study. Am J Med 1971; 51: 352-361.

31. Odds FC. Candida and candidosis, 2nd edn. London, Baillière Tindall. 1988.

32. Gross PA, DeMauro PJ, Van Antwerpen C, Wallenstein S, Chiang S. Number of comorbidities as a predictor of nosocomial infection acquisition. Infect Control Hosp Epidemiol 1988; 9: 497-500.

33. Richet HM, Andremont A, Tancrede C, Pico JL, Jarvis WR Risk factors for candidemia in patients with acute lymphocytic leukemia. Rev Infect Dis 1991; 13: 211-215.

34. Pittet D, Monod M, Filthuth I, Frenk E, Suter PM, Auckenthaler R. Contour-clamped homogeneous electric field gel electrophoresis as a powerful epidemiologic tool in yeast infections. Am J Med 1991; 91: 256S-263S.

35. Pittet D, Monod M, Suter PM, Frenk E, Auckenthaler R Candida colonization and subsequent infections in critically ill surgical patients. Ann Surg 1994; 220: 751-758.

36. Garbino J, Pittet D. Candida infections in the ICU. Clin Intensive Care 1997; 8: 187-200.

37. Sendid B, Tabouret M, Poirot JL, Mathieu D, Fruit J, Poulain D. New enzyme immunoassays for sensitive detection of circulating Candida albicans mannan and antimannan antibodies: useful combined test for diagnosis of systemic candidiasis. J Clin Microbiol 1999; 37: 1510-1517.

38. Field B, Knipe D, Holley P. Diagnostic virology. In: Press L-R (ed) Field's virology, 3rd edn. Philadelphia, Lippincott-Raven Press. 1996: 401-430.

39. Jacquinot PM, Plancke Y, Sendid B, Strecker G, Poulain D. Nature of Candida albicans-derived carbohydrate antigen recognized by a monoclonal antibody in patient sera and distribution over Candida species. FEMS Microbiol Lett 1998; 169: $131-138$

40. Poulain D, Tronchin G, Dubremetz JF, Biguet J. Ultrastructure of the cell wall of Candida albicans blastospores: study of its constitutive layers by the use of a cytochemical technique revealing polysaccharides. Ann Microbiol 1978; 129: 141-153.

41. Poulain D, Tronchin G, Jouvert S, Herbaut J, Biguet J Architecture pariétale des blastospores de Candida albicans: localisation de composants chimiques et antigéniques. [Ultrastructural organisation of Candida albicans blastospore cell wall; localisation of chemical and antigenic components.] Ann Microbiol 1981; 132: 219-238.

42. Faille C, Mackenzie DW, Michalski JC, Poulain D. Evaluation of an enzyme immunoassay using neoglycolipids constructed from Candida albicans oligomannosides to define the specificity of anti-mannan antibodies. Eur J Clin Microbiol Infect Dis 1992; 11: 438-446.

43. Trinel P-A, Faille C, Jacquinot PM, Cailliez J-C, Poulain D 
Mapping of Candida albicans oligomannosidic epitopes by using monoclonal antibodies. Infect Immun 1992; 60: 3845-3851.

44. Richardson MD, Kokki MH. New perspectives in the diagnosis of systemic fungal infections. Ann Med 1999; 31: 327-335.

45. Wenzel RP. Nosocomial candidemia: risk factors and attributable mortality. Clin Infect Dis 1995; 20: 1531-1534.

46. Bodey GP. Candidiasis: pathogenesis, diagnosis, and treatment, 2nd edn. New York, Raven Press. 1993.

47. Maschke M, Dietrich U, Prumbaum M et al. Opportunistic CNS infection after bone marrow transplantation. Bone Marrow Transplant 1999; 23: 1167-1176.

48. Munk PL, Lee MJ, Poon PY et al. Candida osteomyelitis and disc space infection of the lumbar spine. Skeletal Radiol 1997; 26: $42-46$.

49. Sallah S, Semelka R, Kelekis N, Worawattanakul S, Sallah W. Diagnosis and monitoring response to treatment of hepatosplenic candidiasis in patients with acute leukemia using magnetic resonance imaging. Acta Haematol 1998; 100: 77-81.

50. Jones JM. Laboratory diagnosis of invasive candidiasis. Clin Microbiol Rev 1990; 3: 32-45.

51. Herent P, Stynen D, Hernando F, Fruit J, Poulain D. Retrospective evaluation of two latex agglutination tests for detection of circulating antigens during invasive candidosis. $J$ Clin Microbiol 1992; 30: 2158-2164.

52. Jarvis WR. The epidemiology of colonization. Infect Control Hosp Epidemiol 1996; 17: 47-52.

53. van Deventer AJM, Goessens WHF, van Zeij1 JH, Mouton JW, Michel MF, Verbrugh HA. Kinetics of anti-mannan antibodies useful in confirming invasive candidiasis in immunocompromised patients. Microbiol Immunol 1996; 40: 125-131.

54. Martinez JP, Gil ML, Lopez-Ribot JL, Chaffin WL. Serologic response to cell wall mannoproteins and proteins of Candida albicans. Clin Microbiol Rev 1998; 11: 121-141.
55. Moro ML, Vigano EF, Cozzi Lepri A. Risk factors for central venous catheter-related infections in surgical and intensive care units. The Central Venous Catheter-Related Infections Study Group. Infect Control Hosp Epidemiol 1994; 15: 253-264.

56. Marr KA, Seidel K, White TC, Bowden RA. Candidemia in allogeneic blood and marrow transplant recipients: evolution of risk factors after the adoption of prophylactic fluconazole. $J$ Infect Dis 2000; 181: 309-316.

57. Georges E, Garrigues ML, Stynen D, Poirot JL. Spécificité in vitro d'un anticorps monoclonal (Acm) anti-mannane et du latex sensibilisé par cet anticorps au cours de la candidose disséminée expérimentale. J Mycol Med 1991; 1: 21-24.

58. Shinoda T, Kaufman L, Padhye AA. Comparative evaluation of the Iatron serological Candida check kit and the API 20C kit for identification of medically important Candida species. $J$ Clin Microbiol 1981; 13: 513-518.

59. Bougnoux ME, Dupont C, Turner L, Rouveix E, Dorra M, Nicolas-Chanoine MH. Mixed Candida glabrata and Candida albicans disseminated candidiasis in a heroin addict. Eur $J$ Clin Microbiol Infect Dis 1997; 16: 598-600.

60. Hopfer RL, Fainstein V, Luna MP, Bodey GP. Disseminated candidiasis caused by four different Candida species. Arch Pathol Lab Med 1981; 105: 454-455.

61. Sendid B, Bonnin A, Lopez J, Tabouret M, Poulain D, Caillot D. Mannan antigen and antibodies in haematological patients with invasive candidiasis. In: Abstracts of the 10th European Congress of Clinical Microbiology and Infectious Diseases, Stockholm, Sweden, May 28-31, 2000.

62. Flanagan PG, Barnes RA. Fungal infection in the intensive care unit. J Hosp Infect 1998; 38: 163-177.

63. Richardson MD, Kokki MH. Diagnosis and prevention of fungal infection in the immunocompromized patient. Blood Rev 1998; 12: 241-254.

64. Poulain D. Physiopathologie et diagnostic des candidoses systémiques. Lettre de l'Infectiologue 2000; 5: 182-190. 